\title{
BMJ open Smoking and suicidal behaviours in a sample of US adults with low mood: a retrospective analysis of longitudinal data
}

\author{
Lirio S Covey, ${ }^{1}$ Ivan Berlin, ${ }^{2}$ Mei-Chen Hu, ${ }^{3}$ Jahn $\mathrm{K} \mathrm{Hakes}^{4}$
}

To cite: Covey LS, Berlin I, Hu MC, et al. Smoking and suicidal behaviours in a sample of US adults with low mood: a retrospective analysis of longitudinal data. BMJ Open 2012;2:e000876. doi:10.1136/

bmjopen-2012-000876

- Prepublication history and additional figures for this paper are available online. To view these files please visit the journal online (http://dx. doi.org/10.1136/

bmjopen-2012-000876).

For author footnote see end of the article.

Received 17 January 2012 Accepted 15 May 2012

This final article is available for use under the terms of the Creative Commons Attribution Non-Commercial 2.0 Licence; see http://bmjopen.bmj.com

For numbered affiliations see end of article.

Correspondence to

Dr Lirio S Covey;

Isc3@columbia.edu

\section{ABSTRACT}

Objective: To investigate whether: (1) smoking predicts suicide-related outcomes (SROs), (2) prior SRO predicts smoking, (3) smoking abstinence affects the risk of SRO and (4) psychiatric comorbidity modifies the relationship between smoking and SRO.

Design: Retrospective analysis of longitudinal data obtained in wave 1 (2001-2002) and wave 2 (2004-2005) of the National Epidemiologic Survey on Alcohol and Related Conditions.

Setting: Face-to-face interviews conducted with persons in the community.

Participants: US adults ( $\mathrm{N}=43$ 093) aged 18 years or older were interviewed in wave 1 and reinterviewed $(\mathrm{N}=34653) 3$ years later. For the present study, the sample was the subset of persons $(\mathrm{N}=7352)$ who at the wave 2 interview reported low mood lasting 2 weeks or more during the past 3 years and were further queried regarding SRO occurring between waves 1 and 2.

Outcome measures: SRO composed of any of the following: (1) want to die, (2) suicidal ideation, (3) suicide attempt, reported at wave 2. Current smoking reported at wave 2.

Results: Current and former smoking in wave 1 predicted increased risk for wave 2 SRO independently of prior SR0, psychiatric history and sociodemographic characteristics measured in wave 1 (adjusted OR (AOR) $=1.41,95 \% \mathrm{Cl} 1.28$ to 1.55 for current smoking; $A O R=1.32,95 \% \mathrm{Cl} 1.21$ to 1.43 for former smoking). Prior SRO did not predict current smoking in wave 2. Compared with persistent neversmokers, risk for future SRO was highest among relapsers (AOR=3.42, 95\% Cl 2.85 to 4.11), next highest among smoking beginners at wave 2 ( $\mathrm{AOR}=1.82,95 \% \mathrm{Cl} 1.51$ to 2.19$)$ and lowest among long-term (4+ years) former smokers $(\mathrm{AOR}=1.22$, $95 \% \mathrm{Cl} 1.12$ to 1.34 ). Compared with persistent current smokers, risk for SRO was lower among long-term abstainers $(p<0.0001)$ but not among shorter-term abstainers $(p=0.26)$.

Conclusions: Smoking increased the risk of future SRO independently of psychiatric comorbidity. Abstinence of several years duration reduced that risk.

\section{ARTICLE SUMMARY}

\section{Article focus}

To investigate among persons reporting low mood lasting 2 weeks or more during the past 3 years whether:

- smoking predicts SROs (want to die, suicidal ideation, suicide attempt); prior SROs predict smoking;

- smoking abstinence affects the risk of SROs;

- psychiatric comorbidity modifies the relationship between smoking and SROs.

\section{Key messages}

- Current and former smoking ( $<4$ years' reported abstinence) predicted increased risk for SROs independently of prior SROs, psychiatric history and socio-demographic characteristics.

- Prior SROs did not predict future current smoking.

- Compared with persistent current smokers, risk of SROs was reduced with long-term ( $\geq 4$ years) but not with shorter-term ( $<4$ years) abstinence.

Strengths and limitations of this study

- Face-to-face interviews, a longitudinal design, a large representative sample, a validated diagnostic instrument, a comprehensive range of putative predictors that permitted statistical control of the key background factors and comorbidities.

- Only persons with self-reported low mood were questioned about SROs; consequently, no generalisability to other populations.

- The sample did not include persons who had completed suicide.

- No assessment of the effects of medical conditions that are possibly causally related to smoking and to SROs.

- Smoking information was self-reported, not biologically verified.

- No information from adolescents, a high-risk population for both smoking and SROs.

\section{INTRODUCTION}

Suicide is a leading cause of death worldwide. Close to 1 million persons die of suicide 
each year. The WHO predicts that by 2020 suicide deaths will rise to 1.5 million. ${ }^{1}$ Completed suicides are largely predicted by the wish to die, thoughts of suicide and unsuccessful previous suicidal attempts, ${ }^{2}$ making it important to understand the risks posed by suicide-related outcomes (SROs). A history of mental disorders ${ }^{3-5}$ and particular demographic characteristics (female gender, younger age, unmarried status and unemployment) are putative risk factors for suicide and SRO. ${ }^{2}$ Smoking, long known as a major risk factor for numerous medical illnesses, ${ }^{6}$ and recently, for psychiatric outcomes as well, ${ }^{78}$ has received increasing attention for its potential contribution to the risk of completed suicides and SROs. ${ }^{9}$ Nevertheless, whether the association between smoking and suicidal behaviours is causal or correlational remains unclear.

A link between smoking and suicide was observed as early as 1976 by Doll and Peto ${ }^{10}$ in their study of mortality due to smoking in male British doctors. Clinical and epidemiological studies that subsequently investigated the issue are in general, but not universal, agreement in finding a significant association between smoking and suicide and suicidal behaviours. Among studies that focused on SRO, three that used cross-sectional epidemiological data found a positive correlational association between smoking and SRO. ${ }^{11-13}$ Of seven longitudinal studies that also used community-based data, three ${ }^{14-16}$ found that current smoking predicted suicidal behaviours even after controlling for the effects of demographic and psychiatric variables; four studies did not find a positive relationship. ${ }^{17-20}$

The effect of smoking abstinence on risk of SRO is also unclear. A study of young adults followed for 10 years found that recent, but not presurvey, cigarette smoking predicted suicidal thoughts and attempts. ${ }^{14}$ Another study showed higher incidence rates of suicidal ideation among former smokers than never smokers, but the difference was no longer significant after adjustment with depressive disorder, anxiety symptoms and alcohol dependence. ${ }^{16}$ A study based on wave 1 data from the National Epidemiological Survey of Alcohol and Related Conditions (NESARC) initially found that longer duration of abstinence decreased risk for SRO, but this effect disappeared upon controlling for psychiatric comorbidity. ${ }^{21}$

A further question of theoretical and practical importance is whether prior SRO increases the risk of future smoking. In the single study that has addressed this question, longitudinal data obtained from adolescents showed that smoking predicted suicidal ideation and suicide attempts, but prior suicidality was not associated with subsequent smoking. ${ }^{15}$

The present study was conducted to address these conundrums of the smoking-suicide relationship: (1) whether prior smoking predicts SRO; (2) whether prior SRO predicts smoking; (3) whether smoking cessation and its corollary, duration of smoking abstinence, affects risk for SRO and (4) whether these relationships are independent of comorbid psychiatric illness. Also explored were the effects of smoking status changes between the two waves of the NESARC on risk of future SRO. The two-wave format, the large sample and extensive data on psychiatric comorbidity that characterised the NESARC $^{22}$ permitted assessment of these questions.

The survey instrument had asked questions regarding the past occurrence of SRO - want to die, suicidal ideation and suicide attempt, only of persons reporting low mood. This restriction limits the generalisability of findings to the general population, but the much higher occurrence of suicidal behaviours among persons with low $\operatorname{mood}^{3} 4$ provided a more sensitive context for detecting the risk potential of smoking for suicidal behaviours. ${ }^{23}$

\section{METHODS}

\section{Sample}

The NESARC data were collected to obtain a representative national sample of US adults. In wave 1 (2001-2002), face-to-face interviews were completed with 43093 persons aged 18 years or older. The overall response rate was $81.0 \%$. The wave 1 sample was reinterviewed in wave 2 (2004-2005) 3 years later (mean interval $=36.6$ months, $\mathrm{SE}=2.62)$, with a response rate of $80.4 \%(\mathrm{~N}=34653)$ based on the wave 1 sample. The NESARC sample size was chosen to be sufficiently large to produce nationally representative proportions for the study of substance abuse and dependence and mental disorders by demographic group with CIs equal to or smaller than extant studies. Following NESARC guidelines, ${ }^{24}{ }^{25}$ the original NESARC data set was transformed to account for survey design effects and sampling weights upon responses in order to adjust for sample selection procedures, nonresponse from selected households or individuals, oversampling (of young adults, blacks and Hispanics) and non-response at the wave 2 time point. Those weights and survey design effects, employed in other studies based on NESARC data, as well as other methodological details of waves 1 and 2 are described in published NESARC Source and Accuracy Statements. ${ }^{24} 25$

Data for the present study were obtained from a subset of persons $(\mathrm{N}=7352)$ who reported low mood at the wave 2 interview, irrespective of low mood in wave 1 . This subsample was selected for the present analysis because it produced the largest number of persons from whom evaluable information for predicting wave 2 SRO was available. The latter subsample is also referred to herein as the 'at-risk sample'. Persons who did not report low mood were skipped out of the SRO sections in waves 1 and 2. The questions for low mood at the wave 2 interview were: "Since your LAST interview in (month/year), have you ever had a time when you felt sad, blue, depressed, or down most of the time for at least 2 weeks?" and "Since your LAST interview, have you ever had a time, lasting at least 2 weeks, when you didn't care about the things that you usually cared about, or when you didn't enjoy the things you usually enjoyed?" At the wave 1 interview, respondents were asked these same questions referenced to their entire lifetime. 


\section{Variables}

The outcome variables for this study were wave 2 SRO and wave 2 current smoking. The main covariates were prior SRO and smoking status at wave 1 . The individual SRO questions are: "During that time when (your mood was at its [sic] lowest/you enjoyed or cared the least about things), did you...feel like you wanted to die? think about committing suicide? attempt suicide?" Responses to these items were summed to create the total SRO question and measured as a dichotomous variable (none of the three $=0$; any of the three $=1$ ). Respondents who did not report low mood in wave 1 and were not asked the SRO questions were assigned a value of 0 for prior SRO.

The questions on tobacco use at wave 1 are: "In your ENTIRE LIFE, have you ever ... (1) Smoked at least 100 cigarettes? (2) Smoked at least 50 cigars? (3) Smoked a pipe at least 50 times? (4) Used snuff, such as Skoal, Skoal Bandit [sic] or Copenhagen at least 20 times? (5) Used chewing tobacco, such as Redman, Levi Garrett or Beechnut at least 20 times?" Persons who smoked cigarettes, cigars and/or pipes comprised (a weighted) $95.9 \%(3368 / 3497)$ of all tobacco users. Following the coding rule of the NESARC, all tobacco users, including the 129 persons who reported using snuff or chewing tobacco only, were labelled as 'smokers'. A never smoker had responded 'No' to each of the questions regarding lifetime use of at least 100 cigarettes, at least 50 cigars, smoked a pipe at least 50 times, used snuff at least 20 times and used chewing tobacco at least 20 times. A former smoker was a 'Yes' responder to at least one of the prior questions who also reported that he or she had not smoked or used tobacco in the past 12 months. (N.B. Very few, if any, of this latter group would have been experiencing withdrawal; thus, the current study is not an adequate test of post-cessation withdrawal as a predictor of SRO). A current smoker was a 'Yes' respondent who had smoked or used tobacco within the past 12 months. At the wave 2 interview, these same questions on tobacco use were asked with regard to the period since the last interview (in month/year).

The smoking status variable (ie, never, former, current) rather than Diagnostic and Statistical Manual of Mental Disorders, Fourth Edition (DSM-IV) defined nicotine dependence was selected to assess tobacco use because: (1) the adequacy of the DSM-IV criteria as a valid measure of nicotine dependence remains controversial $^{2627}$ and (2) response to the single question on smoking status is easier to elicit in the clinical setting, with more validity, than responses to a multi-item measure of tobacco use for which no consensus, standalone instrument yet exists. ${ }^{26} 27$ To categorise long-term or recent status as never-, former, or current smokers, a change variable was created with the following categories according to their report of smoking at waves 1 and 2: (1) never smoker to never smoker, (2) former smoker to former smoker, (3) current smoker to former smoker, (4) current smoker to current smoker, (5) never smoker to current smoker, (6) former smoker to current smoker and (7) never smoker to former smoker.

Other potential confounders or effect modifiers because of their known correlations with smoking and/or SRO, measured at wave 1, were: demographic characteristics (age, gender, race/ethnicity, marital status, education, employment status, income, urban residence, geographic region) and lifetime measures of DSM-IV Axis I and Axis II disorders. The Axis I disorders were categorised into mood disorders (major depression, dysthymia, bipolar I and bipolar II), anxiety disorders (panic disorder, social phobia, specific phobia, generalised anxiety), alcohol use disorders (alcohol abuse or dependence) and other substance use disorders (drug abuse or dependence). A history of attention deficit hyperactivity disorder (ADHD), queried only at wave 2, was used among the wave 1 predictors, its lifetime quality presumed since the DSM-IV criteria for ADHD include the presence of ADHD symptoms before age 7 . All 10 of the Axis II personality disorders measured in Alcohol Use Disorder and Associated Disabilities Interview Schedule (AUDADIS-IV) (shown in table 1), measured at wave 1 , were included as well.

\section{Assessment}

For both waves 1 and 2, the AUDADIS-IV was administered by interviewers from the US Census Bureau. The reliability and validity of the DSM-IV diagnoses obtained through the AUDADIS-IV have been demonstrated in clinical and general samples in the USA and in other countries. $^{28}$

\section{Statistical analysis}

Weighted percentages and SEs measured the distribution of the covariates (demographic characteristics and lifetime psychiatric variables) reported at wave 1 for the sample with low mood and for the complementary sample of persons with no low mood. $\chi^{2}$ Tests were used to assess differences between comparison groups, for example, the at-risk sample and the complementary sample of NESARC participants who did not report low mood. Unadjusted and adjusted ORs (OR and AOR) and $95 \%$ CIs were calculated from univariate logistic regressions and multivariate logistic regressions, respectively, to assess prediction of wave $2 \mathrm{SRO}$ in the sample of persons reporting low mood. The incidence of SRO at wave 2 (since the wave 1 interview) by smoking status, prior SRO and all other covariates at wave 1 were also calculated. The opposite temporal relationship of prior SRO (reported in wave 1) on future current smoking (reported in wave 2) was tested using the identical covariates for assessing predictors of wave 2 SRO, following Granger. ${ }^{29}$ All models were estimated with the PROC SURVEYLOGISTIC function of SAS statistical software V.9.2, with the results verified through an internal statistical review at the US Census Bureau.

Missing values were replaced through imputation using assignment and allocation methods as described in the NESARC Source and Accuracy Statements. ${ }^{24}{ }^{25}$ Sensitivity 
Table 1 Wave 1 characteristics of the low mood sample and the rest of the NESARC wave 2 sample (weighted percentages (\%) and SE)

\begin{tabular}{|c|c|c|c|c|c|c|}
\hline Variable & $\begin{array}{l}\text { Total wave } 2 \\
\text { sample (\%) }\end{array}$ & SE & $\begin{array}{l}\text { Low mood } \\
\text { sample }(\%)\end{array}$ & SE & $\begin{array}{l}\text { Rest of } \\
\text { sample } \neq(\%)\end{array}$ & SE \\
\hline Sample size & 34653 & & 7352 & & 27301 & \\
\hline \multicolumn{7}{|l|}{ Smoking status } \\
\hline Current smoker & 27.02 & 0.17 & 31.65 & 0.38 & 25.85 & 0.19 \\
\hline Former smoker & 19.58 & 0.16 & 17.84 & 0.28 & 20.02 & 0.17 \\
\hline Never smoker & 53.40 & 0.19 & 50.51 & 0.42 & 54.13 & 0.20 \\
\hline \multicolumn{7}{|l|}{ outcomes } \\
\hline Want to die & 10.17 & 0.10 & 23.35 & 0.26 & 6.82 & 0.10 \\
\hline Suicidal ideation & 8.42 & 0.09 & 19.27 & 0.27 & 5.66 & 0.09 \\
\hline Suicide attempt & 2.35 & 0.04 & 6.09 & 0.17 & 1.40 & 0.04 \\
\hline \multicolumn{7}{|l|}{ Demographics } \\
\hline \multicolumn{7}{|l|}{ Gender } \\
\hline Female & 52.08 & 0.16 & 64.13 & 0.40 & 49.02 & 0.17 \\
\hline Male & 47.92 & 0.16 & 35.87 & 0.40 & 50.98 & 0.17 \\
\hline \multicolumn{7}{|l|}{ Race/ethnicity } \\
\hline White & 70.93 & 0.24 & 71.39 & 0.40 & 70.81 & 0.25 \\
\hline Black & 10.75 & 0.20 & 10.61 & 0.22 & 10.79 & 0.21 \\
\hline Hispanic & 11.56 & 0.10 & 11.20 & 0.15 & 11.65 & 0.12 \\
\hline Asian/Pac. Islander & 4.36 & 0.06 & 3.50 & 0.10 & 4.58 & 0.06 \\
\hline Amer. Indian/Alaska & 2.40 & 0.11 & 3.29 & 0.20 & 2.17 & 0.11 \\
\hline Native & & & & & & \\
\hline \multicolumn{7}{|l|}{ Age (years) } \\
\hline $18-19$ & 4.02 & 0.07 & 4.47 & 0.15 & 3.91 & 0.08 \\
\hline $20-29$ & 17.78 & 0.14 & 19.28 & 0.30 & 17.40 & 0.15 \\
\hline $30-44$ & 30.90 & 0.17 & 32.28 & 0.29 & 30.54 & 0.18 \\
\hline $45-64$ & 31.08 & 0.15 & 31.64 & 0.24 & 30.94 & 0.17 \\
\hline 65 and older & 16.22 & 0.10 & 12.32 & 0.25 & 17.21 & 0.12 \\
\hline \multicolumn{7}{|l|}{ Household income } \\
\hline$<\$ 20000$ & 20.35 & 0.17 & 25.07 & 0.32 & 19.15 & 0.19 \\
\hline$\$ 20000-\$ 34999$ & 19.62 & 0.13 & 20.84 & 0.27 & 19.31 & 0.15 \\
\hline$\$ 35000-\$ 59999$ & 26.27 & 0.16 & 24.85 & 0.31 & 26.63 & 0.17 \\
\hline$\$ 60000$ and over & 33.76 & 0.16 & 29.24 & 0.33 & 34.91 & 0.17 \\
\hline \multicolumn{7}{|l|}{ Marital status } \\
\hline Married & 59.81 & 0.17 & 54.75 & 0.35 & 61.10 & 0.17 \\
\hline Cohabiting & 3.25 & 0.06 & 3.60 & 0.11 & 3.16 & 0.07 \\
\hline Widowed & 6.04 & 0.07 & 5.37 & 0.12 & 6.21 & 0.08 \\
\hline Divorced & 8.45 & 0.06 & 10.73 & 0.19 & 7.87 & 0.07 \\
\hline Separated & 1.98 & 0.04 & 2.98 & 0.12 & 1.73 & 0.04 \\
\hline Never married & 20.46 & 0.17 & 22.57 & 0.33 & 19.93 & 0.17 \\
\hline \multicolumn{7}{|l|}{ Education } \\
\hline Less than high school & 14.65 & 0.13 & 16.25 & 0.26 & 14.24 & 0.14 \\
\hline High school diploma & 29.03 & 0.18 & 29.35 & 0.35 & 28.95 & 0.20 \\
\hline College & 56.32 & 0.22 & 54.40 & 0.38 & 56.81 & 0.23 \\
\hline Unemployed & 7.16 & 0.09 & 12.31 & 0.25 & 5.85 & 0.09 \\
\hline Not unemployed & 92.84 & 0.09 & 87.69 & 0.25 & 94.15 & 0.09 \\
\hline Urban & 28.89 & 0.26 & 30.59 & 0.41 & 28.46 & 0.25 \\
\hline Rural/not in central city & 71.11 & 0.26 & 69.41 & 0.41 & 71.54 & 0.25 \\
\hline Northeast & 19.67 & 0.08 & 18.57 & 0.15 & 19.95 & 0.10 \\
\hline Midwest & 23.15 & 0.16 & 23.52 & 0.32 & 23.05 & 0.21 \\
\hline South & 35.21 & 0.15 & 34.89 & 0.39 & 35.29 & 0.19 \\
\hline \multirow{2}{*}{\multicolumn{7}{|c|}{ Lifetime psychiatric disorders }} \\
\hline & & & & & & \\
\hline \multicolumn{7}{|l|}{ Axis I disorders } \\
\hline Alcohol use & 30.43 & 0.20 & 33.57 & 0.39 & 29.63 & 0.20 \\
\hline Substance use & 10.42 & 0.11 & 15.06 & 0.26 & 9.25 & 0.11 \\
\hline Nicotine dependence & 17.47 & 0.13 & 24.33 & 0.37 & 15.73 & 0.13 \\
\hline Anxiety disorder & 17.88 & 0.17 & 31.00 & 0.34 & 14.55 & 0.17 \\
\hline
\end{tabular}




\section{Table 1 Continued}

\begin{tabular}{|c|c|c|c|c|c|c|}
\hline Variable & $\begin{array}{l}\text { Total wave } 2 \\
\text { sample (\%) }\end{array}$ & SE & $\begin{array}{l}\text { Low mood } \\
\text { sample }+(\%)\end{array}$ & SE & $\begin{array}{l}\text { Rest of } \\
\text { sample } \neq(\%)\end{array}$ & SE \\
\hline Mood disorder & 21.09 & 0.13 & 41.82 & 0.33 & 15.82 & 0.13 \\
\hline $\begin{array}{l}\text { Attention deficit } \\
\text { hyperactivity disorder }\end{array}$ & 2.51 & 0.06 & 5.82 & 0.19 & 1.67 & 0.05 \\
\hline \multicolumn{7}{|l|}{ Axis II disorders } \\
\hline Borderline & 5.89 & 0.08 & 18.44 & 0.28 & 2.70 & 0.07 \\
\hline Schizotypal & 3.93 & 0.06 & 11.20 & 0.24 & 2.09 & 0.05 \\
\hline Narcissistic & 6.18 & 0.08 & 11.88 & 0.23 & 4.74 & 0.08 \\
\hline Avoidant & 2.32 & 0.05 & 6.14 & 0.17 & 1.36 & 0.05 \\
\hline Antisocial & 3.63 & 0.07 & 5.86 & 0.21 & 3.07 & 0.07 \\
\hline Dependent & 0.43 & 0.02 & 1.36 & 0.09 & 0.19 & 0.01 \\
\hline Obsessive-compulsive & 8.07 & 0.10 & 13.50 & 0.31 & 6.69 & 0.09 \\
\hline Paranoid & 4.33 & 0.07 & 9.66 & 0.21 & 2.98 & 0.06 \\
\hline Schizoid & 3.06 & 0.06 & 6.44 & 0.21 & 2.21 & 0.05 \\
\hline Histrionic & 1.80 & 0.04 & 3.68 & 0.15 & 1.32 & 0.04 \\
\hline
\end{tabular}

analyses were performed that included: comparison of the at-risk subsample to the complementary wave 2 NESARC sample; using different sets of control variables with and without education, and census region; and including help-seeking behaviour controls. In response to reviewer concerns, we performed the multiple logistic regression models for assessing prediction of wave 2 SRO and of wave 2 current smoking based on the unweighted data adjusted for design effects. These various sensitivity analyses did not alter the associations between smoking and SRO reported below.

\section{RESULTS}

\section{Wave 1 characteristics}

Table 1 shows weighted percentages by smoking status, SRO taken together and individually, demographic characteristics and psychiatric disorders (DSM-IV Axis I and Axis II) in the sample of persons reporting low mood at wave 1 and the rest of the NESARC sample. Current smoking, SRO and the prevalence of psychiatric disorders were markedly higher among the low mood sample, confirming their at-risk status. Other demographic characteristics previously associated with higher risk of suicide and SROs were also higher in the low mood subsample: more females, more low-income and fewer high-income responders, fewer married and more separated or never married, and more unemployed individuals. Differences by race/ethnicity, age, urban or rural residence and geographic area were also observed.

\section{Effects of wave 1 characteristics on wave 2 SRO}

From here on, reported statistics are for the sample of persons reporting low mood at wave 2. The overall incidence rate of SRO (occurring between the wave 1 and wave 2 interviews) was $28.2 \%(\mathrm{SE}=0.33 \%)$. Table 2 shows weighted percentages and ORs for wave 2 SRO by smoking history, prior SRO and the control variables as reported in wave 1 . Unadjusted ORs and $95 \%$ CI for future SRO are shown as reference points. The AORs and $95 \%$ CIs show significantly higher risk of wave 2 SRO for both wave 1 current smokers $(\mathrm{AOR}=1.41,95 \%$ CI 1.28 to 1.55$)$ and former smokers $(\mathrm{AOR}=1.32,95 \%$ CI 1.21 to 1.43 ) relative to never smokers. The difference in point estimates of risk between current versus former smokers was not significant $\left(\chi^{2}=1.95, \mathrm{p}=0.16\right)$.

The multivariate model showed that SRO in wave 1 is the strongest predictor of a wave $2 \mathrm{SRO}(\mathrm{AOR}=3.49,95 \%$ CI 3.18 to 3.84). Significant independent risk of future SRO was also observed for individuals who were woman, Hispanic, younger, cohabiting, divorced or separated, of lower income, unemployed and resided outside the Northeast region. Of the DSM-IV Axis I disorders, only anxiety $(\mathrm{AOR}=1.08,95 \%$ CI 1.01 to 1.17$)$ and $\mathrm{ADHD}$ ( $\mathrm{AOR}=1.56,95 \%$ CI 1.36 to 1.79 ) showed significantly elevated risk of wave $2 \mathrm{SRO}$; mood disorder was correlated with reduced wave $2 \mathrm{SRO}$ risk ( $\mathrm{AOR}=0.77,95 \% \mathrm{CI}$ 0.70 to 0.84 ). Three of the DSM-IV Axis II disorders, that is, borderline personality, schizotypal and avoidant personality, showed significantly increased risk for wave 2 SRO.

\section{Smoking status change from wave 1 to wave 2}

The great majority of the sample $(90.5 \%)$ did not change their smoking status as never-, former, or current smoker, between waves 1 and 2 (table 3). Among the remaining $9.5 \%$, over half $(5.3 \%)$ had shifted from being current smokers to former smokers; more than a fourth $(2.6 \%)$ were never smokers in wave 1 who became current smokers in wave 2; and a smaller proportion $(<2 \%)$ who were former smokers in wave 1 relapsed to smoking in wave 2 .

\section{Effects on wave 2 SRO}

Table 3 shows AORs indicating significant risk for SRO among all categories of ever smokers relative to the 
Table 2 Weighted percentage of suicide-related outcomes (SRO) ${ }^{*}$ reported in wave 2 by wave 1 characteristics, and unadjusted ORs and AORs for risk of wave 2 SRO among persons reporting low mood at the NESARC wave 2 interview ( $N=7352) \dagger$

\begin{tabular}{|c|c|c|c|c|c|}
\hline Variable & $n / N$ & $\begin{array}{l}\text { Weighted percentage } \\
\text { of wave } 2 \text { SRO }\end{array}$ & SE & OR $\ddagger(95 \% \mathrm{Cl})$ & AOR $\S(95 \% \mathrm{Cl})$ \\
\hline \multicolumn{6}{|l|}{ Smoking history } \\
\hline Current smoker in wave 1 & $809 / 2217$ & 35.73 & 0.64 & 1.77 (1.64 to 1.90$)$ & 1.41 (1.28 to 1.55$)$ \\
\hline Former smoker in wave 1 & $339 / 1280$ & 26.68 & 0.67 & $1.16(1.07$ to 1.25$)$ & $1.32(1.21$ to 1.43$)$ \\
\hline Never smoker in wave 1 & $981 / 3855$ & 23.94 & 0.43 & 1.00 & 1.00 \\
\hline SRO in wave 1 & $1009 / 1940$ & 50.01 & 0.76 & 3.84 (3.60 to 4.10$)$ & 3.49 (3.18 to 3.84$)$ \\
\hline \multicolumn{6}{|l|}{ Demographics } \\
\hline \multicolumn{6}{|l|}{ Gender } \\
\hline Female & $1488 / 5090$ & 28.51 & 0.36 & $1.05(0.98$ to 1.12$)$ & 1.13 (1.04 to 1.22$)$ \\
\hline Male & $641 / 2262$ & 27.54 & 0.59 & 1.00 & 1.00 \\
\hline \multicolumn{6}{|l|}{ Race/ethnicity } \\
\hline White & $1253 / 4295$ & 28.38 & 0.36 & 1.00 & 1.00 \\
\hline Black & $333 / 1352$ & 26.53 & 0.70 & 0.91 (0.84 to 0.99$)$ & 0.84 (0.76 to 0.92$)$ \\
\hline Hispanic & $438 / 1342$ & 30.33 & 0.52 & $1.10(1.04$ to 1.17$)$ & 1.26 (1.16 to 1.36$)$ \\
\hline Asian/Pacific Islander & $47 / 169$ & 22.68 & 0.84 & 0.74 (0.67 to 0.82$)$ & 0.93 (0.82 to 1.06$)$ \\
\hline American Indian & $58 / 194$ & 27.18 & 2.81 & $0.94(0.71$ to 1.25$)$ & 0.69 (0.51 to 0.92$)$ \\
\hline \multicolumn{6}{|l|}{ Age (years) } \\
\hline $18-19$ & $94 / 264$ & 36.65 & 1.73 & 1.00 & 1.00 \\
\hline $20-29$ & $410 / 1287$ & 31.40 & 0.67 & $0.83(0.69$ to 0.98$)$ & 0.77 (0.63 to 0.94$)$ \\
\hline $30-44$ & $750 / 2438$ & 29.32 & 0.62 & $0.75(0.64$ to 0.88$)$ & $0.73(0.60$ to 0.90$)$ \\
\hline $45-64$ & $679 / 2395$ & 26.82 & 0.63 & $0.66(0.56$ to 0.78$)$ & 0.69 (0.56 to 0.84$)$ \\
\hline 65 and older & $196 / 968$ & 20.90 & 0.93 & 0.47 (0.39 to 0.57$)$ & 0.68 (0.54 to 0.86$)$ \\
\hline \multicolumn{6}{|l|}{ Marital status } \\
\hline Married & $836 / 3309$ & 24.87 & 0.49 & 1.00 & 1.00 \\
\hline Cohabiting & $86 / 230$ & 35.58 & 1.67 & $1.67(1.42$ to 1.96$)$ & $1.27(1.07$ to 1.51$)$ \\
\hline Widowed & $128 / 562$ & 24.26 & 1.09 & 0.97 (0.85 to 1.10$)$ & 0.92 (0.78 to 1.07$)$ \\
\hline Divorced & $390 / 1104$ & 36.01 & 0.84 & $1.70(1.57$ to 1.84$)$ & 1.20 (1.10 to 1.32$)$ \\
\hline Separated & $130 / 338$ & 37.93 & 1.78 & 1.85 (1.58 to 2.15$)$ & 1.29 (1.06 to 1.56$)$ \\
\hline Never married & $559 / 2129$ & 30.87 & 0.69 & 1.35 (1.24 to 1.46$)$ & 0.97 (0.87 to 1.09$)$ \\
\hline \multicolumn{6}{|l|}{ Education } \\
\hline Less than high school & $440 / 1358$ & 31.58 & 0.92 & 1.17 (1.04 to 1.32$)$ & 1.09 (0.95 to 1.25$)$ \\
\hline High school diploma & $606 / 2111$ & 28.27 & 0.74 & 1.00 & 1.00 \\
\hline Some college or more & $1083 / 3883$ & 27.08 & 0.35 & $0.94(0.87$ to 1.02$)$ & $1.08(1.00$ to 1.17$)$ \\
\hline \multicolumn{6}{|l|}{ Lifetime psychiatric disorder } \\
\hline \multicolumn{6}{|l|}{ Axis I disorders } \\
\hline Alcohol use & $811 / 2350$ & 32.74 & 0.60 & $1.40(1.31$ to 1.49$)$ & 0.95 (0.87 to 1.04$)$ \\
\hline Substance use & $427 / 1033$ & 38.42 & 0.94 & 1.75 (1.61 to 1.89$)$ & 0.98 (0.88 to 1.09$)$ \\
\hline Anxiety & $843 / 2278$ & 37.57 & 0.60 & $1.72(1.62$ to 1.83$)$ & 1.08 (1.01 to 1.17$)$ \\
\hline Mood & $1217 / 3151$ & 36.62 & 0.48 & 2.04 (1.92 to 2.17$)$ & 0.77 (0.70 to 0.84$)$ \\
\hline $\begin{array}{l}\text { Attention deficit } \\
\text { hyperactivity disorder }\end{array}$ & $208 / 394$ & 51.14 & 1.42 & 2.87 (2.56 to 3.22$)$ & 1.56 (1.36 to 1.79$)$ \\
\hline \multicolumn{6}{|l|}{ Axis II disorders } \\
\hline Borderline & $821 / 1433$ & 55.75 & 0.79 & 4.49 (4.22 to 4.77$)$ & 2.91 (2.69 to 3.16$)$ \\
\hline Schizotypal & $485 / 886$ & 53.41 & 1.26 & 3.44 (3.09 to 3.84$)$ & 1.50 (1.31 to 1.72$)$ \\
\hline Narcissistic & $443 / 993$ & 42.49 & 1.01 & 2.08 (1.89 to 2.29$)$ & $1.03(0.92$ to 1.14$)$ \\
\hline Avoidant & $245 / 446$ & 51.87 & 1.37 & 2.97 (2.66 to 3.32$)$ & 1.29 (1.05 to 1.58$)$ \\
\hline Antisocial & $188 / 395$ & 41.55 & 1.39 & 1.89 (1.68 to 2.13$)$ & $0.85(0.72$ to 1.01$)$ \\
\hline Dependent & $58 / 90$ & 56.90 & 2.90 & 3.44 (2.74 to 4.30$)$ & $1.04(0.76$ to 1.41$)$ \\
\hline Obsessive-compulsive & $377 / 961$ & 36.07 & 1.05 & 1.53 (1.39 to 1.69$)$ & 0.90 (0.80 to 1.00$)$ \\
\hline Paranoid & $364 / 756$ & 45.74 & 1.16 & 2.37 (2.14 to 2.62$)$ & 0.95 (0.82 to 1.10$)$ \\
\hline Schizoid & $210 / 473$ & 43.81 & 1.26 & 2.10 (1.89 to 2.33$)$ & 1.01 (0.88 to 1.16$)$ \\
\hline Histrionic & $129 / 266$ & 44.42 & 1.83 & 2.10 (1.82 to 2.43$)$ & 0.76 (0.63 to 0.93$)$ \\
\hline
\end{tabular}

*SRO: feel like want to die, suicide ideation, suicide attempt; $0=$ none, $1=$ any SRO.

† Missing observations for specific variables: race, 43; Hispanic origin, 2; age, 13; marital status, 4; educational attainment, 70; household income, 2544; unemployed, 28; wave 2 individual SRO, 12-18 'unknown' changed to 'no'. Treatment of unknown values in determination of psychiatric diagnosis variables is known only to original NESARC project staff at National Institute on Alcohol Abuse and Alcoholism. $\neq \mathrm{ORs}$ and $95 \% \mathrm{Cls}$ based on simple regression models estimating wave $2 \mathrm{SRO}$ as a function of an individual predictor variable. §AORs and $95 \%$ Cls based on a multiple logistic regression estimating wave 2 SRO as a function of age, sex, race/ethnicity, marital status, income, education, unemployed status, Census region, urban residence, smoking status, Axis I and Axis II disorders (as described in text) and lifetime SRO prior to wave 1.

AOR, adjusted OR; NESARC, National Epidemiological Survey of Alcohol and Related Conditions; SRO, suicide-related outcome. 
Table 3 Effects on wave 2 suicide-related outcomes (SRO) according to smoking status change as reported in NESARC wave 1 and wave 2 interviews

\begin{tabular}{|c|c|c|c|}
\hline Smoking status in wave 1 to wave 2 & $\mathrm{n} / \mathrm{N}$ & $\begin{array}{l}\text { Weighted } \\
\text { percentage* (SE) }\end{array}$ & $\begin{array}{l}\text { Wave } 2 \text { SRO } \dagger \\
\text { AOR } \ddagger(95 \% \mathrm{CI})\end{array}$ \\
\hline 1. Consistent never smoker (in wave 1 and wave 2) & $897 / 3653$ & $47.8(0.40)$ & 1.00 \\
\hline 2. Long-term former smoker (in wave 1 and wave 2) & 293/1185 & $16.4(0.26)$ & $1.22(1.12$ to 1.34$)$ \\
\hline $\begin{array}{l}\text { 3. Recent former smoker (current smoker in wave } 1 \text {, } \\
\text { former smoker in wave 2) }\end{array}$ & $126 / 393$ & $5.3(0.14)$ & 1.37 (1.16 to 1.63$)$ \\
\hline 4. Persistent current smoker (in wave 1 and wave 2) & $683 / 1824$ & $26.3(0.35)$ & $1.50(1.35$ to 1.66$)$ \\
\hline $\begin{array}{l}\text { 5. New current smoker (never smoker in wave } 1 \text {, current } \\
\text { smoker in wave 2) }\end{array}$ & $82 / 194$ & $2.6(0.10)$ & $1.82(1.51$ to 2.19$)$ \\
\hline \multirow{2}{*}{$\begin{array}{l}\text { 6. Relapser (former smoker in wave } 1 \text {, current smoker } \\
\text { in wave 2) }\end{array}$} & $46 / 95$ & $1.5(0.08)$ & $3.42(2.85$ to 4.11$)$ \\
\hline & \multicolumn{3}{|l|}{$\mathrm{N}=7352 \S$} \\
\hline \multicolumn{4}{|c|}{$\begin{array}{l}\text { *The sampling weight variable in wave } 2 \text { was used. } \\
\text { †Any of three items: want to die, suicidal ideation, suicide attempt. } \\
\text { †AORs are adjusted OR with } 95 \% \text { Cls based on multiple logistic regression of wave } 2 \text { SRO as a function of age, sex, race/ethnicity, marital } \\
\text { status, income, education, unemployed status, Census region, urban residence, smoking status, Axis I and Axis II disorders (as described in } \\
\text { text) and lifetime SRO reported in wave } 1 \text {. } \\
\text { §The seventh group ( } n=8 \text { ), which consisted of persons who were never smokers in wave 1, began to smoke and then stopped smoking in wave } \\
2 \text {, was too small for a valid assessment of risk. } \\
\text { NESARC, National Epidemiological Survey of Alcohol and Related Conditions. }\end{array}$} \\
\hline
\end{tabular}

persistent never smokers. The highest risk was seen for relapsers (former smoker to current smoker) $(\mathrm{AOR}=3.42,95 \%$ CI 2.85 to 4.11$)$; new smokers (neversmoker to current smoker) showed the next highest risk $(\mathrm{AOR}=1.82,95 \% \mathrm{CI} 1.51$ to 2.19$)$; and long-term former smokers (during both wave 1 and 2) showed the least elevated, yet still significant, risk $(\mathrm{AOR}=1.22,95 \%$ CI 1.12 to 1.34$)$. The seventh category consisting of never smokers in wave 1 who reported former smoker status in wave 2 was too small for a valid analysis.

\section{Comparative risks by abstinence duration, relapse and new smoking}

Pair-wise $\chi^{2}$ tests for equality of coefficients permitted a comparison of risk estimates for wave 2 SRO (shown in table 3) between categories of smoking status change. Given the 3-year interval between waves 1 and 2 and the coding requirement that former smoking status is assigned only upon reporting of at least 12 months of abstinence, long-term former smokers (category 2, table 3) would have been abstinent for at least 4 years. Persons who shifted from current smoking in wave 1 to former smoking in wave 2 (category 3 , table 3 ) would have been abstinent for at least 12 months and a maximum of 4 years.

The analysis showed that the AOR for wave 2 SRO among recent former smokers (category 3) did not differ from persistent current smokers (category 4) $\left(\chi^{2} \quad(1)=1.26, p=0.26\right)$. However, long-term former smokers (category 2) showed a significantly lower AOR for wave 2 SRO than persistent current smokers $\left(\chi^{2}(1)=\right.$ $16.9, \mathrm{p}<0.0001)$. These data suggest that a reduction in risk for future SRO with past smoking becomes apparent after a considerable period of abstinence. Of additional interest were the risk estimates associated with re-starting (ie, relapse) and with beginning to smoke in wave 2 .
Compared with persistent current smokers, the AOR for wave 2 SRO was significantly higher for both relapsers $\left(\chi^{2}(1)=56.00, \mathrm{p}<0.0001\right)$ and smoking beginners in wave $2\left(\chi^{2}(1)=4.11, \mathrm{p}=0.04\right)$. Furthermore, the AOR for wave 2 SRO was significantly higher among relapsers than beginning smokers $\left(\chi^{2}(1)=19.0, \mathrm{p}<0.0001\right)$.

\section{Does prior SRO predict smoking?}

A multiple regression model on current smoking in wave 2 was fit using the identical list of control variables for predicting wave $2 \mathrm{SRO}$. This second model did not show a direct effect of prior SRO on wave 2 current smoking. Persons with wave $1 \mathrm{SRO}$ were less likely to report current smoking status at wave 2 than were persons who did not experience SRO in wave 1 ( $\mathrm{AOR}=0.81,95 \% \mathrm{CI} 0.72$ to 0.90$)$.

To understand the temporal relationship between smoking and SRO, the effects of the interaction of wave 1 smoking status (current vs never smoker and former vs never smoker) with history of SRO were examined. Table 4 shows AORs from separate multiple regression models on SRO and on current smoking in wave 2 for combined effects of smoking status and prior SRO reported in wave 1 . Never smokers without a prior SRO at wave 1 comprised the reference group in each model. These analyses did not fundamentally change the finding that smoking predicts increased risk of SRO and that the reverse relationship does not hold but indicates nuanced impact of both SRO and smoking history.

The model on wave 2 SRO (table 4, section a) shows that other characteristics (eg, demographics and psychopathology) being equal: (1) all combinations of smoking status and SRO history had statistically significant risks for wave 2 SRO relative to never smokers without prior SRO and (2) for each smoking category, the risks were considerably greater when the combined group involved a prior SRO. The data also show that 
Table 4 Combined effects of smoking status and prior SRO* reported in wave 1 on a) wave 2 SRO and b) wave 2 current smoking

\begin{tabular}{|c|c|c|c|}
\hline Wave 1 smoking status and wave 1 SRO & $\mathrm{n} / \mathrm{N}$ & $\begin{array}{l}\text { Weighted } \\
\text { percentages (SE) }\end{array}$ & AOR† $(95 \% \mathrm{Cl})$ \\
\hline \multicolumn{4}{|l|}{ a) Effect on wave 2 SRO } \\
\hline Never smoker-no prior SRO (referent) & $550 / 2978$ & $17.5(0.4)$ & 1.00 (NA) \\
\hline Never smoker-prior SRO & $431 / 877$ & $46.8(1.0)$ & 4.12 (3.65 to 4.64$)$ \\
\hline Former smoker-no prior SRO & $187 / 968$ & $20.6(0.8)$ & $1.42(1.28$ to 1.57$)$ \\
\hline Former smoker-prior SRO & $152 / 312$ & $48.2(1.6)$ & 4.58 (3.60 to 5.82$)$ \\
\hline Current smoker-no prior SRO & $383 / 1466$ & $26.6(0.7)$ & $1.56(1.41$ to 1.74$)$ \\
\hline Current smoker-prior SRO & $426 / 751$ & $54.1(1.2)$ & 4.77 (3.70 to 5.87$)$ \\
\hline \multicolumn{4}{|l|}{ b) Effect on wave 2 current smoking } \\
\hline Never smoker-no prior SRO (referent) & $166 / 2978$ & $5.3(0.2)$ & $1.00(\mathrm{NA})$ \\
\hline Never smoker-prior SRO & $28 / 877$ & $4.3(0.4)$ & $0.70(0.60$ to 0.82$)$ \\
\hline Former smoker-no prior SRO & $71 / 968$ & $8.6(0.5)$ & $2.20(1.77$ to 2.31$)$ \\
\hline Former smoker-prior SRO & $24 / 312$ & $6.9(0.6)$ & $1.15(0.83$ to 1.61$)$ \\
\hline Current smoker-no prior SRO & $1204 / 1466$ & $82.7(0.5)$ & 82.9 (73.7 to 93.2$)$ \\
\hline Current smoker-prior SRO & $620 / 751$ & $84.2(0.8)$ & $77.0(57.6$ to 104.8$)$ \\
\hline
\end{tabular}

${ }^{*}$ Any of three items: want to die, suicidal ideation, suicide attempt.

†AORs are adjusted ORs with $95 \%$ Cls based on multiple logistic regression models controlling for demographics and psychiatric history at wave 1 (shown in table 1).

SRO, suicide-related outcome.

former smoking and current smoking, in the absence of prior SRO, are valid predictors of an initial SRO. However, once a person has had a SRO, smoking status history does not change the risk prediction-the risk of recurrence is fully predicted by that prior SRO and the other characteristics. The second model, on wave 2 current smoking (table 4, section b), shows an expectedly substantial likelihood of being a current smoker in wave 2 for current smokers in wave 1, regardless of SRO history. Of interest, prior SRO predicted a contrasting reduction in the likelihood of smoking uptake in wave 2 for former smokers and never smokers.

\section{DISCUSSION}

The main findings from the present sample of persons reporting low mood are: (1) current and past smoking predicted increased risk for SRO independently of demographics, psychiatric factors and prior SRO; (2) long-term smoking abstinence was associated with lower risk than persistent smoking; (3) new smoking due to relapse after a period of abstinence or to initiation of smoking by erstwhile never smokers was associated with an increased risk of SRO relative to persistent smoking; (4) prior SRO did not increase the risk of future smoking.

For three Axis I disorders, that is, mood, alcohol use and substance use, the AORs indicated either insignificant effects or a decreased risk of future SRO. These results differ from the increased risks found in the unadjusted analyses, indicating confounding effects of correlated predictors of SRO, for example, prior SRO and comorbid psychiatric disorders. ${ }^{3-5}$ In further analysis that excluded prior SRO in the multivariate model, a positive predictive effect of mood disorder on future SRO (AOR=2.05, 95\% CI 1.92 to 2.17) was observed, contrary to the reduced effect of mood disorder in the full model that adjusted for prior SRO (results available upon request). This finding exemplifies an instance when collinearity with a stronger predictor (eg, wave 1 SRO) overwhelmed the explanatory power of other predictors with weaker relationships. It is thus remarkable that significant effects of smoking on risk of SRO remained despite the evidence of effect suppression due to confounding. Ranked in decreasing order, the significant predictors of SRO risk in the present sample were: prior SRO, borderline personality disorder, ADHD, schizotypal disorder, current smoking, former smoking, avoidant personality disorder and selected demographic characteristics.

Other than the present one, there have been seven longitudinal epidemiological studies of smoking and SRO. ${ }^{14-20}$ The positive effect of current smoking on future SRO reported here was also observed in three studies. ${ }^{14-16}$ Problems of recall due to the long 10-year interval between data time points could explain the negative finding of the study by Kessler et $a l^{17}$; while the younger age of the samples in two studies ${ }^{19} 20$ could have masked a future effect. Of clinical and public health importance is the finding, first reported here, that longer abstinence from smoking decreased the risk for SRO. The latter observation, not considered in two negative studies regarding past smoking, ${ }^{14}{ }^{16}$ could account for the inconsistent findings. Notably, the divergence according to longevity of abstinence is consistent with evidence for lung cancer and other smoking-related disorders that risk reduction from stopping smoking occurs only after multiple years of abstinence. ${ }^{30} 31$ The worrisome observation that relapsers and new smokers are at even higher risk of future SRO than persistent smokers suggests particular targets for increased therapeutic attention. Finally, the data negated a reverse 
temporal relationship of SRO on smoking, as also seen in a study of adolescents. ${ }^{15}$ Instead, a reduction in risk for future smoking was observed among former and neversmokers with prior SRO in wave 1 compared with their counterparts without prior SRO. Perhaps among those former and never smokers, already inclined towards the pro-health behaviour of not currently smoking, was a subset spurred by the prior SRO to undertake further health-promoting and therapeutic actions, which immunised them against future smoking. Their counterparts who did not experience a prior SRO were less likely to be as self-protective or to seek counselling and similar treatments and were less immunised against resorting to new smoking. The serendipitous observation from the present sample that prior SRO and treatment seeking were well correlated $(\mathrm{r}=0.43, \mathrm{p}=0.0001)$ is consistent with that conjecture.

Strengths and limitations of the study are noted. An important strength is the concomitance of rigorous methods and materials not found in prior work on the smoking-suicide question-face-to-face interviews, a longitudinal design, a large sample, a validated instrument and a comprehensive range of putative predictors that permitted statistical control of key background factors and comorbidities. A further strength is the use of a simple yet meaningful measure of smoking status (ie, never, former or current smoking) that is easy for a questioner to administer and for the respondent to recall and understand. Even so, study limitations call for cautious interpretation of the findings. The present sample comprised the subgroup (22\%) of wave 2 participants $(\mathrm{N}=34653)$ who self-reported low mood during the 3-year interval between the interviews. This selectivity yields findings relevant to mental health settings that are likely to serve persons experiencing mood problems; however, they may not generalise to the rest of the NESARC sample or to the national population. Second, the sample did not include persons who had completed suicide attempts. Using the US rate of 11.1 per 100000 population per year, ${ }^{32}$ the wave 1 sample of 43093 could be expected to include about 14 persons with completed suicides before wave 2 (95\% CI 6.8 to 21.6), introducing a non-trivial, although likely small, selection bias. Third, the present study did not assess the effects of medical conditions that are possibly causally related, albeit in different directions, to smoking and to SRO. Fourth, self-reported smoking information was not biologically validated. Fifth, the NESARC did not obtain information from adolescents, a subgroup with a known high risk for SRO. $^{2}$ Finally, in exploratory unadjusted analyses, predictive effects of current smoking were observed across the individual SRO, whereas past smoking predicted want to die and suicidal ideation but not suicide attempt. Validation and articulation of these preliminary observations need to be accomplished in future work.

The rigorous methodology employed in the NESARC gives eminent credence to the central findings of this analysis - an independent effect of smoking on SRO and the absence of a positive influence of prior SRO on future smoking. These results are consistent with the hypothesis that smoking exerts a contributing, and not simply a correlational, effect on risk of SRO. By contrast, these results are inconsistent with the hypothesis that SRO causes smoking or that a third factor causes both smoking and SRO. The neurobiological, genetic, psychiatric and psychological underpinnings of these associations warrant further investigation. The knowledge gained could advance prevention and treatment options for reducing the prevalence of tobacco use and suicide.

\section{Author affiliations}

${ }^{1}$ Department of Psychiatry, Columbia University, New York State Psychiatric Institute, New York, New York, USA

${ }^{2}$ Département de Pharmacologie, Hôpital Pitié-Salpêtrière-Assistance publique-Hôpitaux de Paris-Faculté de médicine, Université P.\& M. Curie INSERM U894, Paris, France

${ }^{3}$ Department of Psychiatry, Columbia University Medical Center, New York, New York, USA

${ }^{4}$ Center for Administrative Records Research and Applications, U.S. Census Bureau, Maryland, USA

Author footnote

The study is a secondary analysis of data collected by the National Institute of Health-National Institute of Alcohol and Alcohol Abuse of the US government. Before data collection, each respondent was informed of the nature of the survey and its potential uses, ensured of confidentiality and told that participation was voluntary. All participants signed a consent form prior to participating in the interviews. Individual data files are deidentified to prevent full anonymity of participants. Approval for conducting this secondary analysis of previously collected data was not required.

Acknowledgements The authors thank the reviewers of this article for their helpful comments.

Contributors LSC and IB conceptualised this study and together with M-CH designed the analysis. JKH had full access to all the data in the study and takes responsibility for the integrity of the data and the accuracy of the data analysis. LSC was the lead writer of the manuscript. All authors participated in the interpretation of findings and writing of the manuscript. All authors had full access to the statistical reports, tables and the manuscript and take responsibility for the integrity of the data and the accuracy of the data analysis The US Census Bureau, National Institute on Alcohol Abuse and Alcoholism (NIAAA) and other employers of the authors had no role in the study design, implementation of the study, analysis and interpretation of data, in the writing of the report and the decision to submit the article for publication.

Funding The National Epidemiologic Survey on Alcohol and Related Conditions was sponsored by the NIAAA and funded in part by the Intramural Program, NIAAA, National Institutes of Health, with additional support from the National Institute on Drug Abuse. No funding was obtained for this secondary analysis.

Competing interests All authors have completed the Unified Competing Interest form (www.icmje.org/coi_disclosure.pdf). (1) JKH received support from NIAAA through the US Census Bureau for the submitted work; (2) LSC, $\mathrm{IB}$ and $\mathrm{M}-\mathrm{CH}$ received no specific support for this work; (3) IB received occasional honoraria for participating in advisory panels of Pfizer Ltd during the past 3 years; (4) in February 2011, LSC provided educational consultation to a law firm regarding mood effects of smoking cessation; (5) JKH and M-CH had no relationships with any company that might have an interest in the submitted work in the previous 3 years; (6) none of the spouses of the authors had financial relationships that may be relevant to the submitted work; (7) none of the authors had a non-financial interest that may be relevant to the submitted work.

Ethics approval Ethics approval was provided by the US Census Bureau and the US Office of Management and Budget.

Provenance and peer review Not commissioned; externally peer reviewed 
Data sharing statement In order to safeguard sensitive personal information, data are not available for public use. The restricted use data sets are maintained by the US Census Bureau on behalf of NIAAA, and any requests to use NESARC data for replication or other purposes may be directed to the NIAAA coordinator for NESARC, Aaron White (whitea4@mail.nih.gov).

\section{REFERENCES}

1. World Health Organization. Suicide Prevention. 2010. http://www.who. int/mental_health/prevention/suicide/suicideprevent/en/accesssed

2. Nock MK, Borges G, Bromet EJ, et al. Suicide and suicidal behavior. Epidemiol Rev 2008;30:133-54.

3. Tidemalm D, Långström N, Lichtenstein $P$, et al. Risk of suicide after suicide attempt according to coexisting psychiatric disorder: Swedish cohort study with long term follow-up. BMJ 2008;337:a2205.

4. Harris EC, Barraclough B. Suicide as an outcome for mental disorders. A meta-analysis. Br J Psychiatry 1997;170:205-8.

5. Nock MK, Hwang I, Sampson NA, et al. Mental disorders, comorbidity and suicidal behavior: results from the National Comorbidity Survey Replication. Mol Psychiatry 2010;15:868-76.

6. CDC. Health Effects-Smoking \& Tobacco Use. http://www.cdc.gov/ tobacco/basic information/health effects/index.htm

7. John U, Meyer C, Rumpf HJ, et al. Smoking, nicotine dependence and psychiatric comorbidity-a population-based study including smoking cessation after three years. Drug Alcohol Depend 2004;76:287-95.

8. Choi WS, Patten CA, Gillin JC, et al. Cigarette smoking predicts development of depressive symptoms among U.S. adolescents. Ann Behav Med 1997;19:42-50.

9. Hughes JR. Smoking and suicide: a brief overview. Drug Alcohol Depend 2008;98:169-78.

10. Doll R, Peto R. Mortality in relation to smoking, 20 years' observations on male British doctors. BMJ 1976;2:1525-36.

11. Bolton JM, Robinson J. Population-attributable fractions of Axis I and Axis II mental disorders for suicide attempts; findings from a representative sample of the adult, non-institutionalized US population. Am J Public Health 2010;100:2473-80.

12. Scherrer JF, Grant JD, Agrawal A, et al. Suicidal behavior, smoking, and familial vulnerability. Nicotine Tob Res 2012;14:415-24.

13. Yaworski D, Robinson J, Sareen J, et al. The relation between nicotine dependence and suicide attempts in the general population. Can J Psychiatry 2011;56:161-70.

14. Breslau N, Schultz LR, Johnson EO, et al. Smoking and the risk of suicidal behavior: a prospective study of a community sample. Arch Gen Psychiatry 2005;62:328-34.

15. Bronisch T, Höfler M, Lieb R. Smoking predicts suicidality: findings from a prospective community study. J Affect Disord 2008;108:135-45.

16. Clarke DE, Eaton WE, Petronis $\mathrm{KR}$, et al. Increased risk of suicidal ideation in smokers and former smokers compared to never smokers: evidence from the Baltimore ECA follow-up study. Suicide Life Threat Behav 2010;40:307-18.
17. Kessler RC, Borges G, Sampson N, et al. The association between smoking and subsequent suicide-related outcomes in the National Comorbidity Survey panel sample. Mol Psychiatry 2009;14:1132-42.

18. Boden JM, Fergusson DM, Horwood LJ. Cigarette smoking and suicidal behaviour: results from a 25-year longitudinal study. Psychol Med 2008;38:433-9.

19. McGee R, Williams S, Nada-Raja S. Is cigarette smoking associated with suicidal ideation among young people? Am J Psychiatry 2005;162:619-20.

20. Wilcox HC, Anthony JC. The development of suicidal ideation and attempts: an epidemiologic study of first graders followed into young adulthood. Drug Alcohol Depend 2004;76(Suppl):S53-67.

21. Berlin I, Covey LS, Donohue MC, et al. Duration of smoking abstinence and suicide-related outcomes. Nicotine Tob Res 2011;13:887-93.

22. Grant BF, Stinson FS, Dawson DA, et al. Co-occurrence of 12-month alcohol and drug use disorders and personality disorders in the United States: results from the National Epidemiologic Survey on Alcohol and Related Conditions. Arch Gen Psychiatry 2004;61:361-8.

23. Nordentoft M. Prevention of suicide and attempted suicide in Denmark. Epidemiological studies of suicide and intervention studies in selected risk groups. Dan Med Bull 2007;54:306-69.

24. Grant BF, Kaplan K, Shepard J, et al. Source and Accuracy Statement for Wave 1 of the 2001-2002 NESARC. National Institute on alcohol abuse and Alcoholism. Bethesda, MD: National Institute on Alcohol Abuse and Alcoholism, 2003. https://www.fbo.gov/utils/view? id=2f8b6b30ed2a57485da564b32f6e9e60

25. Grant BF, Kaplan KD. Source and Accuracy Statement for the 2004-2005 wave 2 National Epidemiologic Survey on Alcohol and Related Conditions. Bethesda, MD: National Institute on Alcohol Abuse and Alcoholism, 2005. https://www.fbo.gov/utils/view? id $=808$ b8e8cfcaa3c366c39c2ef643a40d5

26. Hughes JR, Baker T, Breslau N, et al. Applicability of DSM criteria to nicotine dependence. Addiction 2011:106:894-5.

27. Mwenifumbo JC, Tyndale RF. DSM-IV, ICD-10 and FTND: discordant tobacco dependence diagnoses in adult smokers. J Addict Res Ther 2011;2:1.

28. Ruan WJ, Goldstein RB, Chou SP, et al. The alcohol use disorder and associated disabilities interview schedule-IV (AUDADIS-IV): reliability of new psychiatric diagnostic modules and risk factors in a general population sample. Drug Alcohol Depend 2008;92:27-36.

29. Granger CWJ. Investigating causal relations by econometric models and cross-Spectral methods. Econometrica 1969;37:424-38.

30. Novello AC. Surgeon General's report on the health benefits of smoking cessation. Public Health Rep. 1990;105:545-8.

31. Cao $\mathrm{Y}$, Kenfield $\mathrm{S}$, Song $\mathrm{Y}$, et al. Cigarette smoking cessation and total and cause-specific mortality: a 22-Year follow-up study among US male physicians. Arch Intern Med 2011;171:1956-8.

32. National Institute of Mental Health, Suicide in the United States, statistics and prevention, NIH Publication No. 06-4594. 56-9. http:// www.nimh.gov 